\title{
Comparison of the effects of acetaminophen to ketorolac when added to lidocaine for intravenous regional anesthesia
}

\author{
Myoung Jin Ko, Jeong Han Lee, Soon Ho Cheong, Chee Mahn Shin, Young Jae Kim, Young Kyun \\ Choe, Kun Moo Lee, Se Hun Lim, Young Hwan Kim, Kwang Rae Cho, and Sang Eun Lee
}

Department of Anesthesiology and Pain Medicine, Busan Paik Hospital, College of Medicine, Inje University, Busan, Korea

Background: This study was done to evaluate the effect on pain relief when acetaminophen was added to lidocaine for intravenous regional anesthesia (IVRA).

Methods: Sixty patients undergoing hand or forearm surgery received IVRA were assigned to three groups: Group C received $0.5 \%$ lidocaine diluted with $0.9 \%$ normal saline to a total volume of $40 \mathrm{ml}(\mathrm{n}=20)$, Group P received $0.5 \%$ lidocaine diluted with intravenous acetaminophen $300 \mathrm{mg}$ to a total volume of $40 \mathrm{ml}(\mathrm{n}=20)$ and Group $\mathrm{K}$ received $0.5 \%$ lidocaine diluted with $0.9 \%$ normal saline plus ketorolac $10 \mathrm{mg}$ made up to a total volume of $40 \mathrm{ml}(\mathrm{n}=20)$. Sensory block onset time, tourniquet pain onset time, which was defined as the time from tourniquet application to fentanyl administration for relieving tourniquet pain and amount of analgesic consumption during surgery were recorded. Following deflation of tourniquet sensory recovery time, postoperative pain and quantity of analgesic uses in post-anesthesia care unit were assessed.

Results: Sensory block onset time was shorter in Group P compared to Group C $(\mathrm{P}<0.05)$. Tourniquet pain onset time was delayed in Group $\mathrm{P}$ when compared with group $\mathrm{C}(\mathrm{P}<0.05)$. Postoperative pain and analgesic consumption were reduced in Group P and Group K compared to Group C $(\mathrm{P}<0.001)$.

Conclusions: The addition of acetaminophen to lidocaine for IVRA shortens the onset time of sensory block and delays tourniquet pain onset time, but not with ketorolac. Both acetaminophen and ketorolac reduce postoperative pain and analgesic consumption. (Korean J Anesthesiol 2010; 58: 357-361)

Key Words: Acetaminophen, Intravenous regional anesthesia, Ketorolac, Paracetamol.

Received: November 27, 2009. Revised: 1st, December 28, 2009; 2nd, January 22, 2010. Accepted: February 27, 2010.

Corresponding author: Jeong Han Lee, M.D., Department of Anesthesiology and Pain Medicine, Busan Paik Hospital, College of Medicine, Inje University, Gaegeum-dong, Busanjin-gu, Busan 614-110, Korea. Tel: 82-51-890-6520, Fax: 82-51-898-4216, E-mail: ljh646@hanmail.net This work was supported by the 2008 Inje University Research Grant.

(c) This is an open-access article distributed under the terms of the Creative Commons Attribution Non-Commercial License (http:// creativecommons.org/licenses/by-nc/3.0/), which permits unrestricted non-commercial use, distribution, and reproduction in any medium, provided the original work is properly cited. 


\section{Introduction}

Intravenous regional anesthesia (IVRA) was first used by August Bier in 1908 [1]. This technique is easy, reliable and costeffective when used in short operative procedures of hand or forearm [2]. Tourniquet pain and lack of postoperative analgesia after tourniquet release are the major limitations to this technique. To improve the efficacy of IVRA, various agents such as tramadol [3], clonidine [4], neostigmine [5] are added to the local anesthetics. Also various nonsteroidal anti-inflammatory drugs (NSAIDs) have been demonstrated to enhance analgesia such as ketorolac, in IVRA [6,7].

Acetaminophen is an analgesic which relieves pain and reduces fever. Perfalgan $^{\mathrm{TM}}$ (Bristol-Myers Squibb, France) is a solution of acetaminophen administrated intravenously in order to relieve pain or reduce fever following surgery.

We planned this study to evaluate the effect of intravenous acetaminophen and ketorolac on sensory block onset times, tourniquet pain and postoperative analgesia when added to lidocaine for IVRA.

\section{Materials and Methods}

Sixty patients with American Society of Anesthegiologists (ASA) physical status I or II, aged between 17 and 60 years, who were scheduled for surgery of the hand or the forearm were included in this study after informed consent. Patients with sickle cell anemia, Raynaud's disease, history of drug allergy, liver disease, kidney disease were excluded from the study.

This prospective, double-blinded, randomized, interventions study, conducted in the patients undergoing hand or forearm surgery were randomly assigned in three groups: Group Cpatients received $0.5 \%$ lidocaine diluted with $0.9 \%$ normal saline

Table 1. Demographic Data, Total Operation Time and Total Tourniquet Application Time

\begin{tabular}{lccc}
\hline & $\begin{array}{c}\text { Group C } \\
(\mathrm{n}=20)\end{array}$ & $\begin{array}{c}\text { Group P } \\
(\mathrm{n}=20)\end{array}$ & $\begin{array}{c}\text { Group K } \\
(\mathrm{n}=20)\end{array}$ \\
\hline Age (yr) & $40.0 \pm 12.5$ & $42.7 \pm 13.9$ & $40.3 \pm 16.2$ \\
Gender (M/F) & $11 / 9$ & $10 / 10$ & $11 / 9$ \\
Weight (kg) & $65.2 \pm 5.9$ & $64.6 \pm 13.6$ & $64.7 \pm 10.8$ \\
Height (cm) & $165.5 \pm 8.0$ & $165.3 \pm 10.7$ & $166.6 \pm 10.0$ \\
Duration of operation (min) & $36.8 \pm 16.9$ & $34.0 \pm 22.1$ & $29.0 \pm 15.1$ \\
Tourniquet application time (min) & $50.2 \pm 14.5$ & $47.3 \pm 13.3$ & $47.6 \pm 13.3$
\end{tabular}

Values are number of patients or mean \pm SD. Group Creceived $0.5 \%$ lidocaine diluted with $0.9 \%$ normal saline to a total volume of $40 \mathrm{ml}$ for IVRA. Group P received $0.5 \%$ lidocaine diluted with intravenous acetaminophen $300 \mathrm{mg}$ to a total volume of $40 \mathrm{ml}$. Group K received $0.5 \%$ lidocaine diluted with $0.9 \%$ normal saline plus ketololac $10 \mathrm{mg}$ to a total volume of $40 \mathrm{ml}$. There are no significant difference among the groups. to a total volume of $40 \mathrm{ml}(\mathrm{n}=20)$, Group P- patients received 0.5\% lidocaine diluted with intravenous acetaminophen 300 $\mathrm{mg}$ (Perfalgan $30 \mathrm{ml})$ to a total volume of $40 \mathrm{ml}(\mathrm{n}=20)$ and Group K- patients received $0.5 \%$ lidocaine diluted with $0.9 \%$ normal saline plus ketorolac $10 \mathrm{mg}$ to a total volume of $40 \mathrm{ml}$ $(n=20)$. There was no significant difference among groups for age, height, weight, duration of operation time, tourniquet time and sex ratio (Table 1). The types of operations performed are presented in Table 2. There were no exclusions from the study due to technical failure.

After the patients had been taken to the operating room, mean arterial blood pressure (MAP), peripheral oxygen saturation $\left(\mathrm{SpO}_{2}\right)$, and heart rate ( $\left.\mathrm{HR}\right)$ were monitored. Before establishing the anesthetic block, two cannulae were placed; one in dorsal vein of the operative hand for anesthetic drug administration and the other in opposite hand for crystalloid infusion. The operative arm was exsanguinated with an Esmarch bandage, and a pneumatic tourniquet was placed around the upper arm. The proximal cuff was inflated to $250 \mathrm{mmHg}$ and maintained in the same position. Circulatory isolation of arm was verified by inspection, absence of radial pulse, and loss of pulse oximetry tracing of the ipsilateral index finger. After the bandage was removed, $40 \mathrm{ml}$ of the respective solutions were injected for the period of 60 seconds.

The sensory block was assessed by a pinprick test using a 22gauge short-beveled needle taken out continuously every 30 seconds. Patient response was evaluated in the dermatomal sensory distribution of the medial and lateral antebrachial cutaneous, ulnar, median, and radial nerves. After sensory block was achieved, the distal cuff was inflated to $250 \mathrm{mmHg}$ followed by release of the proximal tourniquet and operation was then started.

Assessment of tourniquet pain using the visual analog scale

Table 2. Typesof Operations Performed

\begin{tabular}{lccc}
\hline \multicolumn{1}{c}{ The types of operation } & $\begin{array}{c}\text { Group C } \\
(\mathrm{n}=20)\end{array}$ & $\begin{array}{c}\text { Group P } \\
(\mathrm{n}=20)\end{array}$ & $\begin{array}{c}\text { Group K } \\
(\mathrm{n}=20)\end{array}$ \\
\hline Ganglion excision & 3 & 4 & 4 \\
Finger fracture close reduction & 3 & 2 & 0 \\
Carpal tunnel syndrome & 5 & 3 & 5 \\
Radius fracture close reduction & 3 & 1 & 1 \\
Hardware removal of forearm & 2 & 5 & 3 \\
Hand laceration & 3 & 1 & 3 \\
Mallet finger & 1 & 1 & 3 \\
Trigger thumb & 0 & 3 & 1 \\
\hline
\end{tabular}

Values are number of patients. Group Creceived $0.5 \%$ lidocaine diluted with $0.9 \%$ normal saline to a total volume of $40 \mathrm{ml}$ for IVRA. Group P received $0.5 \%$ lidocaine diluted with intravenous acetaminophen $300 \mathrm{mg}$ to a total volume of $40 \mathrm{ml}$. Group K received $0.5 \%$ lidocaine diluted with $0.9 \%$ normal saline plus ketololac $10 \mathrm{mg}$ to a total volume of $40 \mathrm{ml}$. 
(VAS) $(0=$ no pain and $10=$ worst pain imaginable $)$ were monitored at 5, 10, 20, 30 and $40 \mathrm{~min}$ after tourniquet application. Intermittent bolus of $1 \mu \mathrm{g} / \mathrm{kg}$ fentanyl were administrated for tourniquet pain treatment when VAS $>3$. The onset time of tourniquet pain time was recorded (the time elapsed after tourniquet inflation to first patient reported VAS $>3$ ). The total fentanyl consumption for maintaining VAS below 3 was also recorded. During operation if there was no tourniquet pain more than VAS 3, tourniquet pain onset time was accepted as the duration of tourniquet application time.

The tourniquet was not deflated within $40 \mathrm{~min}$ and was not inflated more than 1.5 hours. At the end of surgery, the tourniquet deflation was performed by the cyclic deflation technique (the tourniquet was deflated three times in a cyclic manner with 10 second periods of deflation separated by 1 minute periods of reinflation). Sensory recovery time was noted (time elapsed after tourniquet deflation up to recovery of pain in all dermatomes determined by pinprick test).

Assessment of postoperative surgical pain scores using VAS were checked every $30 \mathrm{~min}$ after tourniquet deflation for 2 hours in postanesthesia care unit and highest VAS of each patient was noted as postoperative VAS score. In postanesthesia care unit, patient received tramadol $50 \mathrm{mg}$ when VAS was $>3$, and total amounts of tramadol administered to each group were recorded.

During the intraoperative period and postoperative period, any local or systemic complications were recorded for 24 hours in the ward.

Statistical analysis was performed with Medcalc ${ }^{\mathrm{TM}}$ for windows version 9.1 (Frank schoonjans, Belgium). Comparison among the groups was made with one-way analysis of variance (ANOVA). Significance was assumed at $\mathrm{P}<0.05$.

Table 3. Onset and Recovery Time of Sensory Block, Tourniquet Pain Onset Time, Intraoperative Fentanyl Consumption and Number of Patients who Required Fentanyl

\begin{tabular}{lccc}
\hline & $\begin{array}{c}\text { Group C } \\
(\mathrm{n}=20)\end{array}$ & $\begin{array}{c}\text { Group P } \\
(\mathrm{n}=20)\end{array}$ & $\begin{array}{c}\text { Group K } \\
(\mathrm{n}=20)\end{array}$ \\
\hline Sensory block & & & \\
$\quad$ Onset time (min) & $3.6 \pm 1.6$ & $2.3 \pm 1.4^{*}$ & $3.1 \pm 1.4$ \\
$\quad$ Recovery time (min) & $3.0 \pm 2.0$ & $2.6 \pm 1.0$ & $3.2 \pm 1.8$ \\
$\begin{array}{l}\text { Tourniquet pain onset time (min) } \\
\text { Intraoperative fentanyl }\end{array}$ & $26.4 \pm 10.7$ & $34.6 \pm 7.8^{*}$ & $28.6 \pm 10.8$ \\
$\quad$ consumption ( $\mu \mathrm{g})$ & $35.3 \pm 33.1$ & $22 \pm 28.7$ & $42 \pm 33.2$ \\
Patients who required fentanyl (n) & 11 & 8 & 13
\end{tabular}

Values are number of patients or mean \pm SD. Group Creceived $0.5 \%$ lidocaine diluted with $0.9 \%$ normal saline to a total volume of $40 \mathrm{ml}$ for IVRA. Group P received 0.5\% lidocaine diluted with intravenous acetaminophen $300 \mathrm{mg}$ to a total volume of $40 \mathrm{ml}$. Group K received $0.5 \%$ lidocaine diluted with $0.9 \%$ normal saline plus ketololac $10 \mathrm{mg}$ to a total volume of $40 \mathrm{ml} .{ }^{*} \mathrm{P}<0.05$ compared with Group C.

\section{Results}

Sensory block onset time was significantly shorter in Group $\mathrm{P}$ than in group $\mathrm{C}(\mathrm{P}<0.05)$. There was no significant difference among groups when compared for sensory block recovery time (Table 3).

There was no significance among groups for intraoperative total amount of fentanyl consumption $(\mathrm{P}=0.093)$. The number of patients who required fentanyl were eleven in Group C, eight in Group P, thirteen in Group C. Tourniquet pain onset time was significantly longer in Group $\mathrm{P}$ than other groups $(\mathrm{P}<0.05)$ (Table 3).

There was no significant difference among groups when compared against VAS scores for tourniquet pain (Table 4).

Postoperative VAS score in Group P and Group K were significantly lower than Group C $(\mathrm{P}<0.001)$ (Table 4). Twelve patients of Group C were given additional analgesic (tramadol $50 \mathrm{mg}$ ) in postanesthesia care unit, whereas four patients of Group $\mathrm{P}$ and only one patient of Group K were given tramadol. The postoperative analgesic consumption was significantly lower in Group P and Group K than group C $(\mathrm{P}<0.001)$ (Table 4).

No patient developed hypotension, hypoxemia, bradycardia or any other adverse events in intraoperative and postoperative period over a period of 24 hours in ward.

\section{Discussion}

The primary outcome of this study was - addition of intravenous acetaminophen to lidocaine for IVRA decreased onset time of sensory block, postoperative pain, postoperative analgesic

Table 4. VAS Scores after Tourniquet Inflation, Postoperative VAS Scores, Tramadol Consumption and Number of Patients who Required Tramadol

\begin{tabular}{lccc}
\hline & $\begin{array}{c}\text { Group C } \\
(\mathrm{n}=20)\end{array}$ & $\begin{array}{c}\text { Group P } \\
(\mathrm{n}=20)\end{array}$ & $\begin{array}{c}\text { Group K } \\
(\mathrm{n}=20)\end{array}$ \\
\hline VAS scores after tourniquet inflation & & & \\
$5 \mathrm{~min}$ & $1.4 \pm 1.3$ & $0.9 \pm 1.2$ & $1.3 \pm 1.3$ \\
$10 \mathrm{~min}$ & $1.8 \pm 1.6$ & $1.2 \pm 1.3$ & $2.0 \pm 1.6$ \\
$20 \mathrm{~min}$ & $2.7 \pm 2.1$ & $2.2 \pm 1.6$ & $3.4 \pm 2.3$ \\
$30 \mathrm{~min}$ & $3.1 \pm 4.4$ & $3.0 \pm 1.8$ & $3.5 \pm 1.8$ \\
$40 \mathrm{~min}$ & $4.3 \pm 2.5$ & $4.5 \pm 2.3$ & $4.2 \pm 1.7$ \\
$\begin{array}{l}\text { Postoperative VAS scores } \\
\text { Postoperative tramadol }\end{array}$ & $3.8 \pm 2.4$ & $2.2 \pm 1.6^{*}$ & $1.4 \pm 1.2^{*}$ \\
$\quad$ consumption (mg) & $30.0 \pm 25.1$ & $10.0 \pm 20.5^{*}$ & $2.5 \pm 11.2^{*}$ \\
Patients who required tramadol (n) & 12 & $4^{*}$ & $1^{*}$ \\
\hline
\end{tabular}

Values are number of patients or mean \pm SD. Group Creceived $0.5 \%$ lidocaine diluted with $0.9 \%$ normal saline to a total volume of $40 \mathrm{ml}$ for IVRA. Group P received $0.5 \%$ lidocaine diluted with intravenous acetaminophen $300 \mathrm{mg}$ to a total volume of $40 \mathrm{ml}$. Group K received $0.5 \%$ lidocaine diluted with $0.9 \%$ normal saline plus ketololac $10 \mathrm{mg}$ to a total volume of $40 \mathrm{ml}$. ${ }^{*} \mathrm{P}<0.05$ compared with Group C. 
consumption and delayed tourniquet pain onset time.

In the pilot study that was conducted we discovered that some of the cases faced a delay in surgery as the motor block was not achieved even after IVRA. Therefore, we did not asses onset and recovery time of motor block in this study. Further studies are therefore required to know the effects on motor block.

It is known that by increase in $\mathrm{pH}$ of local anesthetics improves the nerve penetration and rate of onset of blockade [2], we investigate $\mathrm{pH}$ of each solution used in this study. The $\mathrm{pH}$ of lidocaine-normal saline solution was 6.16 (Group C), and that of lidocaine-normal saline-ketorolac mixture was 6.28 (Group $\mathrm{K})$ and the $\mathrm{pH}$ value of lidocaine-intravenous acetaminophen mixture was 5.88 (Group P). Although the pH of lidocaineintravenous acetaminophen mixture was lower than other groups, onset time of sensory block was much faster in Group P compared to Group C. This effect may be as a result of acetaminophen's antinociceptive effect at pheripheral site.

NSAIDs are widely used concomitantly with IVRA to improve the quality of anesthesia. It is known that the analgesic effect of NSAID is attributed to inhibition of the isoenzyme COX-2 [8] that is primarily associated with inflammation. Cytokines and growth factors enhance the expression and synthesis of COX-2, mainly at inflammatory sites, producing prostaglandins that mediate inflammation, pain and fever [9]. Reuben et al. demonstrated that ketoroloac added to lidocaine improved control of tourniquet pain and postoperative pain [6]. The study also suggested that reduction of postoperative pain is as a result of residual ketorolac in the operative arm, and its redistribution to the systemic circulation after tourniquet deflation [7]. Studies have indicated that optimal dose of ketorolac for IVRA was $20 \mathrm{mg}$ [7], but we used $10 \mathrm{mg}$ of ketorolac, as $30 \mathrm{mg}$ of ketorolac was shown to be equipotent with $1 \mathrm{~g}$ of intravenous acetaminophen [10]. In this study, postoperative pain and postoperative analgesic consumption were decreased in Group $\mathrm{K}$ than Group $\mathrm{C}$ but was ineffective in decreasing tourniquet pain and onset time of sensory block. Ketorolac $10 \mathrm{mg}$ when added to IVRA may be insufficient to reduce tourniquet pain but its anti-inflammatory effect and systemic circulation after tourniquet deflation may reduce postoperative pain.

The main mechanism of analgesic effect of acetaminophen is demonstrated to be through its action on central nervous system mediated by inhibition of prostaglandin synthesis $[11,12]$. Acetaminophen is also shown to inhibit cyclooxygenase (COX) enzyme in vivo [13,14].

In a recent study, paracetamol added to lidocaine for IVRA improved quality of anesthesia and delayed tourniquet pain onset time, reduced intraoperative and postoperative analgesic consumption [15] in which paracetamol $300 \mathrm{mg}$ was added to $40 \mathrm{ml}$ solution for IVRA similar to present study. Sen $\mathrm{H}$ et al. [15] compared the IVRA lidocaine and paracetamol mixture with IVRA lidocaine plus intravenous acetaminophen whereas the present study compared the effects of IVRA lidocaine and acetaminophen mixture vs IVRA lidocaine and ketorolac mixture. The results of this study were comparable to the previous study, except that, in this study intravenous acetaminophen for IVRA did not significantly reduce intraoperative analgesic consumption. The time points of intraoperative analgesic administration were also different. Sen $\mathrm{H}$ et al. [15] used fentanyl for decreasing tourniquet pain when VAS $>4$ but in the present study VAS $>3$ was the cut-off pain score, thus intraoperative analgesics were administered in more number of patients than study conducted by Sen $\mathrm{H}$ et al. [15].

Several studies have demonstrated the peripheral antinociceptive effect of acetaminophen. Lee et al. [16] have suggested that acetaminophen selectively suppressed peripheral prostaglandin E2 release and increased COX-2 gene expression in a clinical model of acute inflammation. In another study, acetaminophen may also interfere with the delivery of peripheral $\beta$-endorphins and help in reducing the pain [17]. Canbay et al. [18] have studied that $50 \mathrm{mg}$ of intravenous acetaminophen pretreatment is effective in reducing the pain on propofol injection. Dani et al. [19] suggested that paracetamol exhibits local antinociceptive effects by modulating cannabinoid receptors.

There were few limitations in this study. The dose of intravenous acetaminophen $300 \mathrm{mg}$ was fixed for the reason that when intravenous acetaminophen over $300 \mathrm{mg}$ was mixed then the total volume of IVRA solution would be too large and would be difficult to control the concentration of lidocaine. We anticipate that larger doses of acetaminophen would increase the efficacy of analgesic during IVRA but optimal dose of acetaminophen could not be determined. Another limitation is that motor block and delayed postoperative pain after patient discharge from postanesthesia care unit were not assessed. The variability in intraoperative pain or postoperative pain depending on the type of surgery performed such as carpal tunnel syndrome, close reduction of radius fracture, ganglion excision etc, could not be standardized (Table 2).

In conclusion, this study indicated that the addition of intravenous acetaminophen to lidocaine in IVRA significantly shortens the onset time of sensory block, but not intravenous ketorolac. The addition of both drugs may not affect intraoperative analgesia and tourniquet pain. However, both drugs would improve postoperative analgesia in postanesthesia care unit.

\section{References}

1. Brill S, Middleton W, Brill G, Fisher A. Bier's block; 100 years old and still going strong! Acta Anaesthesiol Scand 2004; 48: 117-22.

2. Choyce A, Peng P. A systematic review of adjuncts for intravenous 
regional anaesthesia for surgical procedure. Can J Anesth 2002; 49: 32-45.

3. So KY, Kim HJ, Go WS. Intravenous regional anesthesia using mepivacaine and tramadol. Korean J Anesthesiol 2002; 42: 172-6.

4. Gentili M, Bernard JM, Bonnet F. Adding clonidine to lidocaine for intravenous regional anesthesia prevents tourniquet pain. Anesth Analg 1999; 88: 1327-30.

5. Kang KS, Jung SH, Ahn KR, Kim CS, Kim JE, Yoo SH, et al. The effects of neostigmine added to ropivacaine for intravenous regional anesthesia. Korean J Anesthesiol 2004; 47: 649-54.

6. Reuben SS, Steinberg RB, Kreitzer JM, Duprat KM. Intravenous regional anaesthesia using lidocaine and ketorolac. Anesth Analg 1995; 81: 110-3.

7. Steinberg RB, Reuben SS, Gardner G. The dose response relationship of ketorolac as a component of intravenous regional anaesthesia with lidocaine. Anesth Analg 1998; 86: 791-3.

8. Bennett A, Villa G. Nimesulide: an NSAID that preferentially inhibits COX-2, and has various unique pharmacological activities. Expert Opin Pharmacother 2000; 1: 277-86.

9. Crofford LJ. COX-1 and COX-2 tissue expression: implications and predictions. J Rheumatol Suppl 1997; 49: 15-9.

10. Zhou TJ, Tang J, White PF. Propacetamol versus ketorolac for treatment of acute postoperative pain after total hip or knee replacement. Anesth Analg 2001; 92: 1569-75.

11. Aronoff DM, Oates JA, Boutaud O. New insights into the mechanism of action of acetaminophen: its clinical pharmacologic characte- ristics reflect its inhibition of the two prostaglandin $\mathrm{H} 2$ synthases. Clin Pharmacol Ther 2006; 79: 9-19.

12. Remy C, Marret E, Bonnet F. State of the art of paracetamol in acute pain therapy. Curr Opin Anaesthesiol 2006; 19: 562-5.

13. Simmons DL, Botting RM, Robertson PM, Madsen ML, Vane JR. Induction of an acetaminophen-sensitive cyclooxygenase with reduced sensitivity to nonsteroid anti-inflammatory drugs. Proc Natl Acad Sci USA 1999; 96: 3275-80.

14. Botting R. Paracetamlo-inhibitable COX-2. J Physiol Pharmacol 2000; 51: 609-18.

15. Sen H, Kulahci Y, Bicerer E, Ozkan S, Dagh G, Turan A. The analgesic effect of paracetamol when added to lidocaine for intravenous regional anesthesia. Anesth Analg 2009; 109: 1327-30.

16. Lee YS, Kim H, Brahim JS, Rowan J, Lee G, Dionne RA. Acetaminophen selectively suppresses peripheral prostaglandin E2 release and increase COX-2 gene expression in a clinical model of acute inflammation. Pain 2007; 129: 279-86.

17. Sprott H, Shen H, Gay S, Aeschlimann A. Acetaminophen may act through beta endorphin. Ann Rheum Dis 2005; 64: 1522.

18. Canbay O, Celebi N, Arun O, Karagöz AH, Saricaoğlu F, Ozgen S. Efficacy of intravenous acetaminophen and lidocaine on propofol injection pain. Br J Anaesth 2008; 100: 95-8.

19. Dani M, Guindon J, Lambert C, Beaulieu P. The local antinociceptive effects of paracetamol in neuropathic pain are mediated by cannabinoid receptors. Eur J Pharmacol 2007; 573: 214-5. 